\title{
Upaya Peningkatan Kualitas Hidup Melalui Program LAGA (Latihan Fisik dan Yoga) pada Lansia di UPTD Panti Tresna Werdhanirwana Puri Samarinda
}

\author{
Bachtiar Safrudin ${ }^{1}$, Tri Wijayanti ${ }^{2}$ \\ 1,2,University of Muhammadiyah KalimantanTimur \\ e-mail:1mbs143@umkt.ac.id
}

\begin{abstract}
The increasing proportion of the elderly has an impact on the risk of various social and health problems arising from degenerative diseases. Action (Physical Exercise and Yoga) is a combination of the range of motion exercises and yoga that is modified to adapt to the conditions and conditions of the elderly. This study uses a case study method by looking at the differences in the physical activity of the elderly before and after LAGA. The intervention was carried out for 6 actions involving 60 elderly respondents with the criteria of all elderly> 55 years old who lived in a nursing home and did not experience impaired physical mobility due to other diseases. Data from this report shows that there was a change in where the quality of life was bad before the intervention as many as 40 to 36 elderly and good quality of life before the intervention as many as 20 to 24 elderly after intervention. Physical and yoga exercises (fight) affect the quality of life of the elderly. The quality of life of the elderly increases because Laga's interventions have an influence on the physical, psychological, social relations and environment of theelderly.
\end{abstract}

Keywords: Physical Exercise, elderly lifequality, yoga

\begin{abstract}
Abstrak. Bertambahnya proporsi jumlah lansia berdampak pada resiko munculnya berbagaimasalah sosial dan kesehatan baik akibat penyakit degeneratif. Laga (Latihan Fisik dan Yoga) merupakan kombinasi dari latihan rentang gerak dan yoga yang dimodifikasi menyesuaikan dengan kondisi dan keadaan lansia Penelitian ini menggunakan metode studi kasus dengan melihat perbedaaan kemmapuan aktivitas fisik lansia sebelum dan setelah LAGA. Intervensi dilakukan selama 6 kali tindakan yang melibatkan 60 responden lansia dengan kriteria semua lansia yang berusia $>55$ tahun yang tinggal dipanti dan tidak mengalami gangguan mobilitas fisik karena penyakit lain. Data lasil laporan pengabian ini menunjukkan terjadi perubahan dimana kualitas hidup buruk sebelum intervensi sebanyak 40 menjadi 36 lansia dan kualitas hidup baik sebelum intervensi sebanyak 20 menjadi 24 lansia setelah dilakukan intervensi. Latihan fisk dan yoga (laga) berpengaruh terhadap kualitas hidup lansia. Kualitas hidup lansia meningkat karena intervensi Laga memiliki pengaruh terhadap fungsi fisik, psikologik, hubungan sosial dan lingkungan lansia.
\end{abstract}

Kata kunci:Latihan Fisik, kualtias hidup lansia, yoga

\section{Pendahulan}

Usia harapan hidup (UHH) masyarakat Indonesia telah mengalami peningkatan. 
Peningkatan UHH ini berbanding lurus dengan peningkatan jumlah proposi lansia yaitu dari 7,56 \% pada tahun 2010, menjadi 8,49\% pada tahun 2015, diprediksi akan meningkat lagi pada tahun 2020 menjadi 9, 99\%, lalu 11,83\% pada tahun2 025,13,82 pada tahun 2030 dan 15,77\% pada tahun 2035 (WHO, 2013). Menurut Stanhope dan Lancaster (2016) mengatakan lansia sebagai populasi beresiko ini memiliki tiga karakteristik risiko kesehatan yaitu, risiko biologi termasuk risiko terkait usia, risiko sosial dan lingkungan serta risiko perilaku atau gaya hidup. Bertambahnya proporsi jumlah lansia berdampak pada resiko munculnya berbagai masalah sosial dan kesehatan baik akibat penyakit degeneratif seperti diabetes, penyakit jantung, ginjal, stroke dan gangguan pembuluh darah maupun masalah kesehatan yang diakibatkan menurunnya masalah fungsional tubuh seperti resiko disabilitas yang mengakibatkan tingkat kemandirian lansia berkurang dan pada akhirnya akan memengaruhi kualitas hidup lansia.

Kenyataan tersebut menjadi isyarat perlunya peningkatan pelayanan kesehatan yang lebih fokus pada lansia karena dengan peningkatan jumlah lansia mereka akan beresiko dan bahkan mengalami kerentanan sebagai kelompok penggunan pelayanan kesehatan karena berbagai masalah kesehatan yang muncul akibat penurunan fungsi fisiologis tubuh. Permasalahan kesehatan yang dialami lansia tersebut tidak akan menjadi masalah yang serius jika program penanganan dan penatalaksanaan dilakukan secara komprehensif yang meliputi upaya pencegahan primer, sekunder dan tersier.

Hal tersebut menjadi tantangan bagi perawat komunitas untuk menjalankan peran dan fungsinya secara optimal dalam memberikan asuhan keperawatan yang berfokus pada lansia yang selama ini belum berjalan dengan optimal, sehingga upaya yang dilakukan dapat menjadi solusi untuk mencegah permasalahan yang lebih kompleks pada lansia, menjadikan lansia hidup sebagai individu yang berkualitas dan tidak menjadi beban bagi keluarga, masyarakat dan pemerintah.

Miller (2012) menggambarkan bahwa risiko lansia untuk mengalami masalah kesehatan merupakan dampak yang terjadi akibat bertambahnya usia, dan sering kali lansia akanmengalami banyak kehilangan (multiple loss). Kehilangan terjadi akibat perubahan fisik, psikososial, kultural maupun spiritual.

Perubahan fisik pada lansia terjadi sebagai akibat adanya perubahan fisiologis pada berbagai sistem tubuh diantaranya perubahan pada sistem muskuloskeletal, sistem sensoris, sistem integumen, sistem neurologis, sistem kardiovaskular, sistem pulmonal, sistem endokrin, sistem renal dan urinaria, sistem gastrointestinal serta sistem reproduksi. 28 | Upaya Peningkatan Kualitas... 
Perubahan pada berbagai sistem tubuh tersebut dapat memicu munculnya penyakit degeneratif lansia seperti dimensia, osteoartritis, jantung hipertensi, stroke dan diabetes. Upaya mempertahankan kesehatan lansia merupakan salah satu program yang perlu dilakukan untuk meningkatkan kualitas hidup lansia.

Kualitas hidup merupakan persepsi individu rentan posisi dan keadaan mereka dalam hidup dalam konteks budaya dan sistem nilai dimana mereka hidup, hal ini berhubungan dengan tujuan, harapan, standar serta target yang ditetapkan oleh mereka masing-masing (WHO, 2013). Kualitas hidup secara konsep terdiri dari kesehatan fisik individu, kesejahteraan psikososial dan fungsi, kemandirian, kontrol atas kehidupan, keadaan materi, dan lingkungan eksternal (Brett, Gow, Corley, Pattie, Starr \& Deary, 2012). WHOQOL merupakan instrumen yang dapat mengukur kualitas hidup individu yang terdiri dari 6 komponen besar yaitu kesehatan fisik, psikologi, tingkat kemandirian, hubungan sosial, lingkungan dan spiritualitas (WHO, 2012). Konsekuensi fungsional yang dialami lansia merupakan manifestasi dari Tindakan atau faktor risiko dan penuaan yang selanjutnya berdampak pada kualitas hidup lansia dan aktivitas sehari-hari lansia (Miller, 2012).Penurunan fungsi menyebabkan melemahnya beberapa sistem dalam tubuh lansia, salah satunya adalah sistem muskuloskeletal. Perubahan sistem muskuloskeletal seperti terjadinya perubahan struktur tubuh, tulang, ligamen, tendon, otot, dan sendi. Lansia akan mengalami gangguan pembentukan sel-sel tulang, terjadinya gangguan pembentukan tulang sekunder/tulang rawan, dan rendahnya penyerapan kalsium. Otot mengalami penurunan massa, penurunan sensasi neuromotorik, kekakuan jaringan ikat dan gangguan penggantian jaringan otot. Penurunan fungsi otot akan menurunkan kekuatan, kelenturan, kecepatan dan ketahanan rentang gerak, yang berefek pada terbatasnya ruang gerak. Lansia mengalami kehilangan control postur tubuh yang berakibat meningkatnya goyangan tubuh terutama saat berdiri.Terjadinya gangguan koordinasi tubuh. Lansia akan lambat berespon. Lansia berjalan dengan lambat dan kurang berespon terhadap rangsangan lingkungan, sehingga pergerakan lansia mengalami gangguan (Miller, 2012). Hal ini memengaruhi tingkat kemandirian lansia yang menyebabkan status fungsional menurun.

UPTD Panti Sosial Tresna Werdha Nirwana Puri Samarinda yang terletak di Jalan Mayjend Sutoyo, merupakan unit panti sosial bagi lansia dari berbagai daerah. Panti sosial ini memilikiluas areal kurang lebih $20.850 \mathrm{~m} 2$ dengan total bangunan 37 buah, dan total wisma berjumlah 15 wisma.Hasil temuan yang didapat pada bulan Januari 2017 di UPTD Panti Tresna Werdha Nirwana Puri Samarinda, didapat data bahwa daya tampung Bachtiar \& Tri $\mid 29$ 
keselurahan lansia di panti tersebut berjumlah 120 orang. Pada bulan Januari 2017, lansia yang tinggal dipanti berjumlah 117 orang, diantaranya terdiri dari 63 orang perempuan dan 54 orang laki-laki.

Data yang ditemukan di UPTD Panti Tresna Werdha Nirwana Puri Samarinda terdapat lansia yang mengalami masalah-masalah degeneratif diantaranya hipertensi, diabetes militus, insomnia, gangguan psikososial, gangguan perawatan diri, gangguan mobilitas. Proses degeneratif ini akan berdampak pada Kualitas hidup lansia, sehingga membutuhkan intervensi keperawatan yang tempat dalam mengatasi maslah tersebut.

Menurut Miller (2012) menjelaskan bahwa berbagai intervensi keperawatan untuk lansia dapat dilakukan melalui penatalaksanaan yang komprehensif yang meliputi pencegahan primer, sekunder dan tersier. Bentuk pencegahan primer yang sudah diupayakan di UPTD Panti Tresna Werdha Nirwana Puri Samarinda meliputi program nutrisi dan aktivitas jasmani. Tindakan-tindakan tersebut sebenarnya dapat dimasukan kedalam program pengembangan dan pemeliharaan kesehatan lansia yang dilaksanakan di UPTD Panti Tresna Werdha Nirwana Puri Samarinda, akan tetapi kondisi saat ini penatalaksanaan lansia secara komprehensif belum dilakukan secara optimal. Hal tersebut dapat menimbulkan risiko semakin meningkatnya jumlah lansia yang mengalami masalah kesehatan seperti penyakit tidak menular sehingga dapat menyebabkan kualitas hidup lansia menurun. Berdasakan hal tersebut maka diperlukan upaya penatalaksanaan yang komprehensif meliputi pencegahan primer,sekunder dan tersier melalui intervensi secara fisik, psikologis, sosial dan spiritual, sehingga lansia dapat memepertahankan kualitas hidupnya secara optimis.

\section{Metode}

Pengabdian masyarakat ini hanya melihat hasil output dari intervensi LAGA dalam meningkatkan kualitas hidup yang dilihat pada lansia. Intervensi dilakukan selama 6 kali tindakan yang melibatkan 60 responden lansia dengan kriteria semua lansia yang berusia $>55$ tahun yang tinggal dipanti dan tidak mngelami gangguan mobilitas fisik karena penyakitlain.

Alat pengumpulan data yang digunakan dalam pengabdian masyarakat ini adalah format pengkajian kualitas hidup dengan meng- gunakan WHOQOL-BREF. Instrumen ini mengukur 4 komponen penting yaitu komponen fisik, psikologis, hubungan sosial dan 30 | Upaya Peningkatan Kualitas... 
lingkungan. Instrumen ini terdiri 26 item pertanyaan yang telah mewakili komponen yang akan diukur dari kualitas hidup. Kuesioner ini menggunakan skala Likert dengan rating scale dari 1-5. Nilai reliabilitas yang ditunjukkan oleh nilai Cronbach's alpha antara 0,84-0,88 dan nilai validitas menunjukkan nilai $r=0,75$. Data yang diambil adalah pengukuran kualitas hidup sebelum dan setelah dilakukan pengabdian masyarakat tanpa dilakukan analisa data secara statistik.

\section{Hasil dan Pembahasan}

Setelah dilakukan intervensi pada 60 responden didapatkan terjadi perubahan hambatan aktivitas responden sebelum dan seteleh dilakukan latihan LAGA sebanyak 6 kali sesi sebagai berikut:

Tabel. 1 Gambaran preintervensi LAGA dan setelah Intervensi LAGA

\begin{tabular}{cccc}
\hline & Kualitas hidup buruk & Kualitas hidup baik & Total \\
\hline Pre Laga & 40 & 20 & 60 \\
\hline Post Laga & 36 & 24 & 60 \\
\hline
\end{tabular}

Sumber : DataPrimer

Berdasarkan hasil pengabdian masyarakat yang dilakukan di UPTD Tresna Werdha Nirwana Puri Samarinda didapatkan perubahan signifikan yang terjadi pada lansia yang dilakukan intervensi Laga. Lansia dengan kualitas hidup buruk 40 lansia menjadi 36 lansia.Latihan fisik dan yoga merupakan kombinasi latihan yang diajarkan pada lansia. Latihan fisik sangat penting dilakukan lansia, dimana latihan fisik yang dilakukan secara teratur dapat meningkatkan hubungan sosial, meningkatkan kesehatan fisik dan mental lansia. Selain itu, yoga berperan penting dalam mengurangi risiko penyakit dan memelihara fungsi tubuh lansia (Ko \& Lee, 2012). Menurut Chung (2008) latihan dapat mencegah kelelahan fisik karena meningkatkan fungsi kardiovaskuler, sistem saraf pusat, sistem imun dan sistem endokrin dan menurunkan gejaladepresi.

Kata Yoga berasal dari bahasa sansekerta yang terdiri dari kata Yuj dan Yoking dengan arti penyatuan secara harmonis dari yang terpisah (Sindhu, 2007). Penyatuan yang harmonis tersebut merupakan proses penyatuan antara tubuh, pikiran, perasaan dan spiritual (Stiles, 2002). Pelatihan Yoga adalah pelatihan yang didesain sesuai kebutuhan para praktisinya yang bentuk latihanya ringan dan lembut yang berdampak pada fisik, mental dan emosional dan juga merupakan pelatihan yang baik untuk mengurangi resiko jatuh 
pada lansia dan meningkatkankeseimbangan.

Efek pelatihan yoga berpengaruh terhadap tubuh manusia, dimana saat melakukannya akan ditunjang dengan pernafaasan dan meditasi. Proses ini akan mempengaruhi tubuh melakukan detoksifikasi racun (Widyantoro, 2008). Ketika orang melakukan latihan yoga akan memberikan nutrisi pada otak, kelenjar dan organ tubuh, sehingga tubuh menjadi lebih sehat (Everada, 2008).

Yoga merupakan intervensi yang dapat diterima dan aman serta dapat menghasilkan perbaikan klinis yang relevan dalam rasa sakit dan fungsional yang berhubungan dengan kondisi muskulosketal. Dari Penelitian yang sudah di lakukan oleh peneliti-peneliti lainya di berbagai negara mengenai latihan yoga yang mempunyai banyak manfaat untuk lansia, salah satunya yaitu dapat meningkatkankeseimbangan.।

Peningkatan kualitas hidup dari latihan fisik dan yoga memang sangat relevan sesuai dengan penelitian Park, Han, dan Kang (2014) mengatakan bahwa program latihan padalansia efektif meningkatkan kualitas hidup, harga diri dan menurunkan gejala depresi. Sejalan dengan yang dilakukan oleh Sun, Aodeng, Tanimoto, Watanabe, dan Han (2015) yang menyebutkan menjaga kesehatan adalah upaya untuk untuk meningkatkan kualitas hidup pada lansia di komunitas.

Menurut penelitian Lai, Leung, Kwong, dan Lee (2015) melakukan penelitian di Hongkong yang menunjukkan bahwa nyeri merupakan salah satu faktor yang dapat menurunkan kualitas hidup lansia di nursing home resident. Penurunan kualitas hidup disebabkan oleh keterbatasan fungsi tubuh, penyakit, pendidikan, rendahnya pendapatan dan kurang berhubungan dengan orang lain (Tavares, Dias, Santos, Hass, dan Miranzi, 2013).

Latihan fiisk dan yoga (Laga) dapat mengkompensasi penurunan fungsi sistem muskuloskeletal. Secara fisiologis, latihan fisik dan yoga dapat meningkatkan range of motion, kekuatan otot, total kalsium tubuh, memperbaiki koordinasi tubuh, mencegah kehilangan massa otot dan memperbaiki fungsi tubuh (Miller, 2012). Hal ini akan meningkatkan kualitas hidup karena lansia merasa lebih sehat untuk beraktivitas.

Latihan meningkatkan koordinasi neuromuscular (Miller, 2012). Menurut penelitian yang dilakukan Marques, Sánchez dan Vicario (2014) menyebutkan 48 lansia di Portugal mengatakan bahwa kualitas hidup berarti memiliki tubuh yang sehat, mendapatkan kedamaian, keharmonisan hidup, merasa bahagia, kepuasan hidup, melakukan kegemaran, terbinanya hubungan dengan teman dan tetangga. 32 | Upaya Peningkatan Kualitas... 


\section{Simpulan}

Dari hasil pengabdian masyarakat ini dapat disimpulkan bahwa intervensi LAGA efektif untuk menunjukan meningkatkan kualitas hidup pada lansia setelah dilakukan selama 6 sesi tindakan. Data lasil laporan pengabian ini menjukkan terjadi perubahan dimana kulaitias hidup buruk sebelum interevnsi sebanyak 40 menjadi 36 lansia dan kaulitas hidup baik sebelum intervensi sebanyak 20 menjadi 24 lansia setelah dilakukan intervensi. Latihan fisk dan yoga (laga) berpengaruh terhadap kualitas hidup lansia. Kualitas hidup lansia meningkat karena intervensi Laga memiliki pengaruh terhadap fungsi fisik, psikologik, hubungan sosial dan lingkungan lansia. Saran untuk tindak lanjut dari pengabdianiniadalah dilakukan dengan penelitian lanjutan terkait dengan variabel lain yang dapat dipengaruhi dari intervensi Laga ini.

\section{Daftar Pustaka}

Brett, C.E., Gow, A.J., Corley, J., Pattie, A., Starr, J.M., \& Deary, I.J. (2012). Psychosocial factors and health as determinants of quality of life in community-dwelling older adults. Qual Life Res, 21, 505-516. doi: 10.1007/s11136-011-9951-2.

Chung, H.A. (2008). A literature review a program of intervention of patient geriatric depression. Society of Occupational Therapy for the Aged and Dementia, 2 (1), 59-67.

Everada, E. (2008). Kenapa Yoga Baik untuk Kesehatan dan Kebahagiaan? Yoga for Health aVoice of Bali edisi 4, April 2008 hlm 4. Bali: Penerbit Yayasan Bali-India Fondation

Ko, J.E., \& Lee, S.H. (2012). A multilevel modeling of factors affecting depression among older Korean adults. Mental Health \& Social Work, 40 (1), 322-351

Lai, C.K.Y., Leung, D.D.M., Kwong, E.W.Y., \& Lee, R.L.P. (2015). Factors associated with the quality of life of nursing home residents in Hongkong. International Nursing Review, $62,120-129$.

Marques, E.M.B.G., Sanchez, C.S., \& Vicario, B.P. (2014). Perception of the quality of life of a group of older people. Revista de Enfermagem Referência, 4 (1), 73-81. doi: 10.12707/RIII1314.

Miller, C.A. (2012). Nursing for wellness in older adult: Theory and practice (6th Ed.).Philadelphia: Lippincott Williams \& Wilkins.

Park, S.H., Han, K.S., \& Kang, C.B. (2014). Effects of exercise programs on depressive symptoms, quality of life, and self-esteem in older people: A systematic review of randomized controlled trials. Applied Nursing Research, 27 (4), 219-226. doi: 10.1016/j. 
apnr.2014.01.004.

Sindhu, P. (2007). Hidup Sehat dan Seimbang dengan Yoga. Bandung: Qanita

Stanhope, M., \& Lancaster, J. (2016). Public health nursing population centered health care in the community (9th Ed.). Missouri: Elsevier.

Stiles, M. (2002). Structural Yoga Therapy: Adapting to The Individual. New Delhi: Goodwill PublishingHouse

Sun, W., Aodeng, S., Tanimoto, Y., Watanabe, M., Han, J., Wang, B., Kono, K. (2015). Quality of life (QOL) of the community- dwelling elderly and associated factors: A 116 Jurnal Keperawatan Indonesia, Vol. 21, No. 2, Juli 2018, hal 109-116 population-based study in urban areas of China. Archives of Gerontology and Geriatrics, 60 (2), 311-316. doi: 10.1016/j.archger.201 4.12.002.

Tavares, D.M.S., Dias, F.A., Santos, N.M.F., Hass, V.D., \& Miranzi, S.C.S. (2013). Factors associated with the quality of life of elderly men. Rev Esc Enferm USP, 47 (3), 673-680. doi: 10.1590/S0080-623420130000300022.

WHO. (2013). World health statistics 2013. Geneva: WHO press.

WHO. (2012). Global Health Observatory (GHO) data. Retrieved 17 Maret 2015, from http://www.who.int/gho/ncd/en/

Widyantoro, Y. (2008). Yoga. Diktat Intensive Classic Yoga di Balance Mind-Body-Soul.Yogyakarta: tidak diterbitkan. 